\title{
Integrating customer data into customer relationship management strategy: An empirical study
}

Received: 4th January, 2001

\begin{abstract}
Julie Abbott
is the Influencer Marketing Manager for IBM's Global Business Intelligence Solutions EMEA, working with industry analysts and a number of European business schools. Before becoming a marketer in 1995, Julie was a systems engineer specialising in IBM's own mainframe technologies. Julie graduated from IBM's own marketing school and holds the Chartered Institute of Marketing's (CIM) post-graduate Diploma, and a Masters in Marketing from Manchester Business School. She is a full member of CIM and a Chartered Marketer.
\end{abstract}

\section{Merlin Stone}

is IBM Professor of CRM, Bristol Business School, UK; Executive Consultant, Business Innovation Services, IBM; Director, QCi Ltd. and Swallow Information Systems Ltd. He is the author of 20 books and many journal articles on CRM and related topics. His research focuses on definitions, strategies and models of customer management, success and failure in implementation of new approaches to customer management, the relationship between e-business and customer management, and data protection and privacy issues.

\section{Francis Buttle}

is Littlewoods Professor of Customer Relationship Management, Manchester Business School, UK. He has nearly 30 years' experience in marketing management, education, consultancy and research. He has lived and worked on three continents Europe, Australasia and North America and has published over 180 items including three books. His most recent book, published in 1996, is an edited volume on the theory and practice of relationship marketing. His teaching and research interests include customer retention, service quality, customer relationship management and management in service industries.

\begin{abstract}
Results are reported from empirical research designed to reveal the level of deployment of customer data in customer relationship management (CRM) strategies. Much of the CRM literature assumes that companies have extensive customer databases, populated with clean, usable data, collected on a regular basis and used to ensure customers are satisfied. This assumption is questioned.

Participants were from various industries, but with a high proportion of technology-based businesses. All the companies surveyed were embracing CRM to some degree but the level of implementation depended on the industry, and size and age of the company in question. Small, niche players are furthest along the way. Large, older mass-market companies appear slower to change. None of the respondents report having a completely up-to-date, clean and usable set of customer data or a fully-implemented CRM strategy.
\end{abstract}

Julie Abbott

Tel: $+44(0) 1788890447$ e-mail:

ABBOTJL@uk.ibm.com

\section{INTRODUCTION}

This paper describes the research and findings of a project aimed at how UK companies use customer information in their CRM strategies. Technologies such as data warehousing and data mining 
allow companies to collect, store, analyse and manipulate enormous volumes of data. This can be important for marketers trying to provide better service and more satisfaction to the customer than competitors. But is it in general use?

\section{LITERATURE REVIEW}

\section{Basic issues}

Kotler discusses the creation and management of customer databases stating that 'one key use of the computer is to manage the prospect and customer database'. ${ }^{1}$ He looks forward to 2005 and predicts that by then all companies will have moved to CRM, making heavy use of data. This implies that the CRM is currently in its infancy. When companies truly embrace CRM, managing the customer database will be a small part of what is needed from the available technology. Data will be central to the business and will be routinely mined for insight and information which will then be rapidly and appropriately deployed.

This theme is taken up by McKenna who focuses on the speed of information dissemination and communication: 'Managers hoping to serve them must work to eliminate time and speed constraints'. ${ }^{2}$ Customers expect the right information (or marketing communication) at the right time and become dissatisfied if this is not achieved. It is not clear if marketers today are ready to do this.

Reichheld stresses the importance of data for measurement purposes as companies strive to achieve customer loyalty. 'It's hard to overestimate its importance in determining the future course of a business ... Measurement turns vision into strategy and strategy into fact'. Of course it is not just measurement per se that matters but the right measures. 'The gateway to the loyalty revolution is developing the right kind of measurement system', he writes. ${ }^{3}$

Buttle echoes the above. Companies 'are now beginning to talk about share of customer (in addition to share of market), economies of scope (as well as economies of scale) and customer loyalty (instead of brand loyalty). Share of customer, a reference to the percentage of an individual's annual or lifetime purchases that is won by a company, is employed as a measure of (C)RM performance'. ${ }^{4}$

Clearly, customer data also have relevance for the marketing planning process. Although Kotler ${ }^{5}$ discusses different types of plan that need to be developed and their contents, he does not detail the computer power and data needed to execute the planned strategies effectively. Fifield (1998) discusses how customers are changing and the need for marketers also to develop and change, mostly by working co-operatively with customers. ${ }^{6}$ This requires customer insight and affirms the need for strategic planning that is flexible.

In stark contrast, Mintzberg argues that plans and "planning itself breeds a basic inflexibility in organizations, and so a resistance to significant change'. ${ }^{7}$ This would significantly hinder the move to CRM by established companies who are firmly entrenched in their current strategies and planning processes. The expectation would therefore be to see that small, young companies are faster to embrace CRM.

Thurbin shows how new ways of strategic thinking deliver benefits to the organisation. Information is always the key: 'Successful organisations are becoming increasingly reliant on being able to create new knowledge - at the same time it is imperative that they make the best use of the old!"

A central activity in CRM strategy is exploiting customer insight and information to create profitable customer 
relationships. As Buttle writes, 'Marketing is no longer about developing, selling and delivering products. It is progressively more concerned about the development and maintenance of mutually satisfying long-term relationships with customers'? He concludes that, 'Enduring relationships with customers cannot be duplicated by competitors, and therefore provide for a unique and sustained competitive advantage'. ${ }^{10}$ This is a view endorsed by Tzokas and Saran who also comment 'relationships henceforth developed with customers become core competencies of the firm which, owing to the uniqueness of the individuals involved, become non-imitable by other firms'. ${ }^{11}$ Furthermore, according to Grant and Schlesinger, 'achieving the full profit potential of each customer relationship should be the fundamental goal of every business. The logic is as simple as it is compelling: Profits from customer relationships are the lifeblood of all businesses'. ${ }^{12}$

A key message in CRM is that in mature markets, the cost of keeping a customer is far less than obtaining a new one. Kaplan and Norton write, 'Clearly, a desirable way for maintaining or increasing market share in targeted customer segments is to start by retaining existing customers in those segments'. ${ }^{13}$ This is an objective helped immensely by holding the right information about customers. Related CRM performance measures are share of wallet (or customer spend) and customer lifetime value. These need accurate historical and forecast data. In the words of Christopher, Payne and Ballantyne, 'Increasingly, organizations are coming to recognize the opportunities for using database marketing whereby the profiles of existing customers are analysed to correlate their demographic and other characteristics with their purchase patterns'. ${ }^{14}$
Customer relationships and the knowledge needed to sustain them are the focus of this research. Stone discusses how to set up the database as well as the processes and management policies around it. He describes different data types and explains why each is needed. 'As a general rule,' he writes, 'the more information a company has, the better the decision'. ${ }^{15}$ This is the heart of the authors' research question - how many companies are embracing CRM and implementing the processes and technology needed to ensure its success?

\section{Industry insight}

A number of studies have explored the degree of CRM development and implementation across industries. As Buttle argues, 'Although the shift to [C]RM is widespread, it is occurring more rapidly in some sectors and industries than others, facilitated by fundamental cultural shifts within organizations, powerful databases and new forms of organizational structure'. ${ }^{16}$

One survey by Cap Gemini and IDC on CRM adoption in 300 large enterprises found that 'almost half of the companies surveyed were still in the planning stage of the [CRM] project. ${ }^{17}$

A number of studies are dedicated to single industries - especially the Close to the Customer series. ${ }^{18}$ This has papers on industries such as retail, airlines, utilities, automotive, insurance and banking. The briefing on airlines observes that there is "no doubt that the honours for international service success have gone to those airlines which have decided which customers they want to deliver top-class international services to'. ${ }^{19}$

McKinsey's report into banking indicates that this industry is at the forefront of the CRM revolution, but that there is still room for improvement. 
'In particular, customer acquisition and management processes will have to be adapted and channels co-ordinated'. ${ }^{20}$

\section{Technology}

As customer numbers increase and/or companies become larger and more remote from customers, technology is increasingly important to CRM strategy development and implementation. Many papers address the use of technology, particularly in the area of data management. ${ }^{21}$

O'Connor and Galvin describe many aspects of marketing's use of information technology (IT) including data warehouses and databases. They are great advocates of technology. 'IT is so powerful in marketing because it is enabling organisations to build powerful personal relationships with their customers and to understand their needs'. ${ }^{22}$

According to Stone, ${ }^{23}$ "Although the term "data warehousing" is becoming a popular term, not many marketing managers really understand what it means, and fewer have experience of real warehousing projects. Most companies even those experiencing major gains still consider themselves to be learning how to use it.' This indicates a gap between installation and successful use of the available technology.

This is confirmed by Shaw ${ }^{24}$ who believes that 'the amount of information held on customers today is truly startling' but goes on to say that 'the average British household receives over 100 items of direct mail annually ... with over half of these thrown away unread'. This suggests that although there is a wealth of data available, they are not being used effectively to improve the return on investment.

A huge growth is being seen in the purchase of database technology needed to enable CRM. One recent study has traced investment in IT to support CRM. In 1998, IT spend worldwide was computed at $\$ 2 \mathrm{bn}$, in 2001 estimated at $\$ 5$ bn and by 2005 is forecast to be $\$ 10 \mathrm{bn} .^{25}$ 'Overall, organisations have invested and are continuing to invest in accessing and sharing information in areas of their business where benefits are immediate - eg marketing, ${ }^{26}$

Although different authors express different viewpoints on CRM, all argue that IT and the wealth of data available are accelerating the overall pace of change. They all agree that better information is fundamental in moving from transactional marketing to CRM, increasing loyalty and keeping the right customers, resulting in better profits and lower costs. But, do marketers have and use large, clean customer databases? Are they all trained in the theory and practice of CRM, and empowered to effectively use it? Or, does reality reflect McDonald's comment? 'Too many companies believe that all they have to do is collect large amounts of data and they will finally be able to meet those (ludicrous) cross-selling objectives. Ah, the power to annoy more customers, faster and at greater cost - heaven! ${ }^{27}$

\section{METHODOLOGY}

\section{Research question}

The basic research question, derived from this literature review, was as follows:

'To what extent are companies collecting, storing and manipulating customer data in order to develop and implement more effective CRM strategies?'

From the literature review it was hypothesised that, although technology now allows enormous amounts and diverse types of data to be held, with 
sophisticated methods of interrogation, marketers generally have neither the level of data nor the tools to exploit the data. Indeed, it was felt they may not even be aware of some of the tools, eg tools to allow complex segmentation, tighter product or campaign targeting and the control of those campaigns. This shortcoming must be inhibiting the speed of implementation of CRM strategies.

\section{Data collection}

The research was conducted in two stages, an e-mail survey of 40 respondents from UK industry, followed by face-to-face or telephone interviews with a subsample of 20 e-mail survey respondents.

This paper reports the findings from Stage 1 of the research. Data were collected from heads of marketing departments or groups. The e-mail survey was designed to collect more quantitative data that could then be used in conjunction with the second set of qualitative responses. Three respondents gave their permission to be short case studies, which are to be published later. Some additional research was done via the Internet to enhance the case study data.

\section{Respondent demographics}

Of the 40 respondents, 66 per cent came from an IT, software or services company. Other sectors included manufacturing, marketing consultancy, retail, utilities, petrochemicals and not-for-profit. The companies ranged from those with a global presence (62 per cent) to those who concentrated on serving the UK market. This was matched with an employee or company presence in the served markets - the main anomaly being one luxury goods company who had a global presence but was staffed entirely from the UK.

Ninety-five per cent of the companies with a global presence were well established (over 25 years of age). Others working globally were new companies with IT offerings.

Over 55 per cent of the respondents worked for companies with an annual turnover of over $\$ 500 \mathrm{~m}$. Twenty per cent of these operated solely in the UK and were spread across retail, utilities and finance sectors. Typically, the companies with a high turnover had a large number of employees and were long established companies (older than 25 years and with over 5,000 employees). One exception was a company in the insurance sector with a turnover of $£ 500 \mathrm{~m}$ and between 1,000 and 5,000 employees, all based in the UK. It is under 25-years old and well known for revolutionising its industry. This company did not take part in the second stage. The sample companies were predominantly business-to-business, although around 25 per cent had some consumer focus. No fast moving consumer good companies were represented.

Most of the respondents have worked for their company for less than ten years (70 per cent), 15 per cent for between ten and 20 years and 7.5 per cent for between 25 and 30 years. A further 7.5 per cent declined to comment. All were from marketing or customer service departments and 17.5 per cent of them were directors or general managers. A further 37.5 per cent were managers either of people, products, customers or markets/programmes. The balance were professionals from specialist areas in marketing - for example marcoms and channels, or declined to comment. Most had been in these roles for less than two years (55 per cent).

Of those giving their gender, 57.5 per cent of the respondents were male and 35 per cent female. Most people were in 
Table 1: Marketing department responsibilities

\begin{tabular}{lcl}
\hline Responsibility & Position & $\%$ \\
\hline Planning/strategy & 1 & 77.5 \\
Brand management & 2 & 72.5 \\
Advertising/PR & 3 & 70 \\
Market intelligence & 4 & 62.5 \\
Database marketing & 4 & 62.5 \\
Field sales & 6 & 57.5 \\
Database marketing & 6 & 57.5 \\
Customer service & 6 & 57.5 \\
Telemarketing & 9 & 55 \\
Relationship marketing & 10 & 52.5 \\
Telesales & 11 & 47.5 \\
Call centre & 12 & 37.5 \\
Other & 13 & 20 \\
\hline
\end{tabular}

the age range of $26-45$ (80 per cent), only 2.5 per cent were younger, and the rest between 46-55. There were various qualifications among respondents, including MBAs and professional degrees - mainly engineering, marketing or other business. The majority (62.5 per cent) had some marketing qualification - from the CIM advanced certificate, to an MA. Again, this figure was skewed due to a high take up of CIM qualifications within the IT industry.

\section{RESULTS}

\section{Marketing department information}

The breadth of responsibilities of marketing groups within respondent companies was investigated. As Table 1 shows, the top three areas of responsibility were planning/strategy, brand management and advertising/PR. These are all concerns of traditional marketing departments. Database marketing and market intelligence were ranked equal fourth.

Had CRM been a major responsibility in marketing departments associated activities would have been expected to be cited more frequently. Database marketing, direct marketing and relationship marketing are all, however,
Table 2: Campaign types

\begin{tabular}{lcl}
\hline Campaign Type & Position & $\%$ \\
\hline Editorial & 1 & 90 \\
Targeted mailing & 2 & 85 \\
Trade shows & 3 & 82.5 \\
Conferences & 4 & 80 \\
Press adverts & 5 & 77.5 \\
Seminars & 6 & 75 \\
Telemarketing & 6 & 75 \\
Customer references & 8 & 72.5 \\
Offers and discounts & 9 & 67.5 \\
Roadshows & 9 & 67.5 \\
Executive events & 9 & 67.5 \\
Other adverts & 12 & 65 \\
Hospitality & 13 & 62.5 \\
Telesales & 14 & 60 \\
Web based & 14 & 60 \\
Focus groups & 16 & 57.5 \\
User groups & 17 & 52.5 \\
Television adverts & 17 & 52.5 \\
Mass mailing & 19 & 47.5 \\
Packaging & 20 & 40 \\
Loyalty schemes & 21 & 32.5 \\
Competitions & 22 & 30 \\
Other & 23 & 12.5 \\
\hline
\end{tabular}

subordinate to the traditional areas of responsibility. Only 20 per cent of companies had other types of marketing group: web enablement, events, marketing communications, pricing, new product development, after sales service and design. Almost 70 per cent of the sample felt that their links with product developers were at best only good half of these were only fair or even poor, and only 15 per cent thought that they had an excellent relationship with the product developers. The time spent with customers varied dramatically. Only a quarter of marketers spent time with their customers on at least a weekly basis.

Questions were asked about the types of campaign that marketing departments managed. As Table 2 shows, certain types were more popular than others. Although all the respondents work for companies that are embracing CRM and feel that a benefit of better data is improved targeting, the top campaign type did 
not involve data-based targeting. Even if specialist magazines, newspapers and journals are chosen for editorial campaigns there is still no control over the audience who read them. This result may reflect on the industries in the survey - over 70 per cent were from IT-based companies and the press are key influencers in this sector. It may also show that companies are now aware that customers have more faith in articles written by the press than supplier-sourced marketing material.

Targeted mail shots were second with 85 per cent of the marketers using this tactic as opposed to only 47.5 per cent who do mass mailings. All of the latter also do targeted mailshots. Less than half of this 85 per cent are confident that only 50 per cent of their data are accurate and should be used for targeting (but which 50 per cent?). This could lead to a lot of potential wastage, increasing costs and potential customer dissatisfaction.

One way to increase the quality of data is to motivate or reward customers for giving their details — via competitions and loyalty schemes for example, but both of these are at the bottom of the campaign-type list.

Traditional events and shows were still favoured by the majority of the respondents despite the huge expense and often poor turnouts, but using customers as a reference was also popular. Over 72 per cent of the marketers use this tactic. Web-based campaigns are used by the majority and this can be expected to rise. The different forms of advertising were ranked lower in the list than expected - although this could be a factor of the industries represented in the survey. Many different campaign types were employed. Sixty-seven per cent of the marketers used over 50 per cent of the campaign types listed in the table.

\section{Customer interaction}

Over half of the companies in the survey used a mix of mail (including e-mail), intermediaries, and direct contact (including face-to-face and telephone) to access their customers. Direct methods of customer contact were used by 95 per cent of respondents; 65 per cent used intermediary channels.

\section{Brand or customer management?}

Around a third of respondents worked for companies (or divisions of a company) with a single brand and at the other end of the scale, 17.5 per cent had 'numerous' or 'too many' brands within their company/division or felt that the question was not applicable to them. Over 60 per cent had between one and ten brands within the company/division as a whole.

When looking at the number of brands that the respondents' marketing groups had responsibility for, this changed the picture with nearly 50 per cent looking after a single brand and a further 40 per cent looking after between two and ten brands. Nearly two thirds of respondents worked in a group that was responsible for all of the brands within their company/division. From the respondents' job titles it appeared that marketers still focus on brand rather than customer management.

\section{Budgets and targets}

Over half of the respondents worked for companies that had an overall marketing budget in excess of $£, 5$ million per annum, and 27 per cent were in marketing groups that also had a budget in this category. The company marketing budget was carried by 15 per cent of the respondents. Apart from one exception, these respondents worked in a marketing group that was responsible for all the 
company's brands and so it could be expected that they would hold this budget.

Eighty per cent of respondents cited revenue as the top target; 57.5 per cent cited profit as one of their targets.

Awareness and market share were higher at 60 per cent. A third were targeted with increasing their share of customer spend/wallet and another third with reducing attrition (65 per cent of these wanted to do both). Over half were looking to increase market penetration despite the (supposed) higher costs of this as opposed to keeping current customers. (55 per cent of this latter group also were targeted on reducing customer loss.)

One eighth of the respondents had all seven of the targets mentioned in the questionnaire, ie increased market share, profits, revenue, awareness, share of customer and new market penetration and reduction of customer attrition, while 10 per cent had six of the seven.

\section{Measurement}

Respondents were asked to list the metrics which were employed to assess achievement of the targets. Cited frequently were sales (80 per cent), lead generation (65 per cent) and expense-to-revenue ratios (60 per cent). There was then a fairly big drop to customer loyalty (42.5 per cent), customer lifetime value (20 per cent) and improved share of customer spend (15 per cent).

It would appear that even if marketers are adopting CRM, their metrics are out of alignment. Perhaps colleagues in other functions such as sales, finance or accounts, or senior management still require reports in terms of short-term measures. It may just be a reflection on the newness of CRM within the company - that the understanding is there but the business processes have to catch up.
Three quarters of respondents had some sort of computerised tracking/measurement mechanisms in place and 60 per cent had many systems rather than one. This may just be a reflection of the size of the company, but does also suggest a level of complexity that could lead to error if care is not taken.

\section{Databases}

The customer database was owned by marketing in 65 per cent of responses; 17.5 per cent said it was owned elsewhere in the company. The balance had no database that they were aware of and used other company or external data. Of respondents with a database, 55 per cent used external or other company data as well as their own customer data. This either shows a lack of confidence in the accuracy of the customer database, or that more complex types of data are needed for some types of campaign.

Eighty per cent of respondents used their database in campaigns, with over 40 per cent of respondents accessing it on a daily basis. A further 25 per cent accessed it on a weekly basis, and a steady decrease was shown as the access frequency reduced - 15 per cent monthly, 10 per cent quarterly, 2.5 per cent every six months and 2.5 per cent annually.

The databases range from less than one year old (10 per cent) to over ten years old (20 per cent) with the majority being somewhere in the middle (52.5 per cent). The vast majority of the data come from marketing or other internal sources. Forty-five per cent of respondents did, however, purchase external data. Seventy-two and a half per cent input data from campaigns, 15 per cent from loyalty programmes, 60 per cent from sales team input and 62.5 per cent from purchase information. Only 20 per cent held competitive information. 
Table 3: Data types held

\begin{tabular}{lll}
\hline Data Type & Position & Percentage of respondents with this type \\
\hline Basic customer information & 1 & 75 \\
Campaign history & 2 & 62.5 \\
Other historical data & 3 & 60 \\
Buy patterns/purchase & 4 & 50 \\
Market information & 5 & 42.5 \\
Competitor information & 5 & 42.5 \\
Forecasts & 7 & 25 \\
Other & 8 & 10 \\
Don't know & 9 & 2.5 \\
\hline
\end{tabular}

This clearly shows that the majority of databases in the survey have multiple information sources.

Only 10 per cent had total confidence in the accuracy and quality of their data. Thirty-two and a half per cent had confidence that they were accurate 75 per cent of the time, and the same percentage again were confident of 50 per cent accuracy. Seven and a half per cent had little or no confidence in the data they held. But as was seen earlier, 80 per cent of respondents still use the data for campaigns.

As Table 3 shows, the more traditional types of data are commonly but not universally held. This would suggest that, despite the acknowledgement of the importance of data for CRM strategy development and implementation, they are not yet implemented everywhere. This could be for many reasons,

Table 4: Computerised tools for campaign management

\begin{tabular}{lcl}
\hline Marketing tool & Position & $\begin{array}{l}\text { Percentage } \\
\text { using this } \\
\text { tool }\end{array}$ \\
\hline Spreadsheets & 1 & 87.5 \\
Internet & 2 & 82.5 \\
Data mining & 3 & 70 \\
Personalised printing & 4 & 65 \\
Call centre & 5 & 60 \\
Planning & 6 & 45 \\
Campaign manager & 7 & 42.5 \\
Online data analysis & 8 & 30 \\
Decision support & 9 & 27.5 \\
Other & 10 & 7.5 \\
\hline
\end{tabular}

including lack of buy-in from the rest of the company (a culture change is often needed for CRM), lack of technology or budget to run campaigns to collect these data, or simply the sheer difficulty of getting them.

\section{Marketing tools used}

There are many computerised tools that can help marketers run effective campaigns through customer databases. Table 4 outlines the better-known tools and the percentage of respondents currently using them.

This shows the huge take up of the Internet within marketing, but the tried and trusted spreadsheet is still used by most. Other tools to help the onset of CRM such as data mining, campaign management software and call centres are gaining ground, but some of the more specialised analytical tools, such as data mining, are still only used by a minority.

\section{The effect of data on marketing}

Respondents were asked how important they felt data to be in contemporary marketing management. A massive 92.5 per cent of respondents agreed that more data would help marketers. Five per cent believed, however, they did not and 2.5 per cent declined to answer. A few people added the comment that better data were needed - not just more. As 
Table 5: How data have influenced marketing practice since 1995

\begin{tabular}{lll}
\hline Difference from 1995 & Position & \% \\
\hline Targeted marketing & 1 & 80 \\
Segmentation & 2 & 65 \\
Keep the right customers & 3 & 47.5 \\
Trend analysis & 4 & 45 \\
Increased loyalty & 5 & 42.5 \\
Customised offers & 6 & 32.5 \\
Increased share of customer & 7 & 27.5 \\
Other & 8 & 10 \\
\hline
\end{tabular}

Table 5 shows, data have made a difference over the last five years to how marketers work.

Many respondents commented on the influence of data. Illustrative comments follow:

'Now it is much more targeted.'

'I still do not believe that we have got enough data to enable us to do all of the things on the list although I wish that we had.'

'Things are not a great deal better because as well as the data collected, what is needed is a different approach to customers/markets by the company.'

'We are going in the right direction, but slowly.'

'Quality of data isn't any better now than before.'

'Our ability to customise offers is affected by other areas.'

'Targeted marketing is the most important point.'

'Cleaner, more easily accessed data is also a benefit.'

\section{Moving to CRM}

The majority of respondents were currently implementing CRM (55 per cent), with 2.5 per cent saying there was
Table 6: Why move to CRM?

\begin{tabular}{lll}
\hline Why move to CRM? & Position & \% \\
\hline Will increase profits & 1 & 45 \\
Will lose business if do not & 1 & 45 \\
Technology allows it & 3 & 40 \\
Customer focused & 4 & 35 \\
Customer demand & 5 & 32.5 \\
Data allows it & 6 & 30 \\
Competition are doing it & 7 & 27.5 \\
Not moving to CRM & 8 & 7.5 \\
Other & 8 & 7.5 \\
\hline
\end{tabular}

Table 7: The importance of CRM

\begin{tabular}{lll}
\hline & $\%$ & Position \\
\hline Extremely & 37.5 & 1 \\
Very & 32.5 & 2 \\
Somewhat & 17.5 & 3 \\
A little & 2.5 & 5 \\
Not at all & 5 & 4 \\
\hline
\end{tabular}

no need for CRM in their company. The other respondents were evenly divided, with 12.5 per cent each for 'always used CRM', 'have used CRM for some time' and 'looking at CRM'.

Only 20 per cent of respondents said there would be little or no change in company policy needed to move to CRM, 2.5 per cent said it would be a complete change and 70 per cent thought that significant changes would be needed.

Table 6 shows why the companies are moving to CRM. It is obvious from the answers that most are adopting CRM because they believe it is good for business. This is not to suggest that they do not care about their customers, but they prioritise business requirements. Respondents were asked how important successful CRM deployment was to business performance. Table 7 suggests that for the majority, CRM is deemed extremely or very important.

Despite the claimed importance of CRM, only 17.5 per cent of all 
respondents believed that their company understood their customers very well. However 70 per cent felt that they had some knowledge. A minority (15 per cent) felt that they had little or no understanding of their customers. Successful CRM implementation, including perhaps one-to-one marketing, requires closeness to customers. The results show that the majority of the sampled companies have some way to go if they are to embrace fully the accepted view of CRM.

\section{CONCLUSIONS}

CRM is an important area of activity. Some 80 per cent of respondents said that they were embracing CRM either implementing it at present, had been working this way for some time, or had always worked this way.

Respondents believed that the amount of data that marketers now have is of benefit. Around half believed that the data enabled them to keep the right customers, improve customer share and/or increase customer loyalty. A majority of around 62 per cent said the data helped them to improve their marketing, getting to the right audiences via better segmentation, targeting and improved trend analysis coupled with better offers.

The majority believe CRM is key to the future performance of the company. A large majority do not, however, understand their customers well enough today. This was compounded by over 50 per cent having very little direct customer contact and running the more 'traditional' campaigns - mail shots and events.

All respondents agreed that the customer data held are not as good as they should be. Interestingly, the IT companies often hold less accurate data than others. There is an imbalance between respondents having only 'some' degree of confidence in the data yet reporting that they are critical to CRM success.

The link between marketing and product development is weak in many companies, but on the whole is better than that between marketing and customers. Interestingly, it was the IT respondents who reported weaker links than other companies. The implications of this are that marketing is not always seen as an integral part of the new product development process (which in the CRM-world should be customer-driven) and that some companies are too introspective.

If it is true, as many claim, that 'what gets measured gets managed', then full CRM adoption may be difficult to achieve. Currently, measurement and target systems are typically based on the traditional areas such as revenue, leads and expense-to-revenue ratios, rather than share of customer and loyalty.

\section{References}

1 Kotler, P (1999) 'Kotler on Marketing', Simon \& Schuster UK Ltd, London.

2 McKenna, R. (1997) 'Real Time', Harvard Business Press, Boston.

3 Reichheld, F. F. (1996) 'The loyalty effect', Harvard Business School Press, Boston.

4 Buttle, F. (1996) 'Relationship marketing: Theory \& practice', Paul Chapman Publishing Ltd, London.

5 Kotler, P. (1999) op. cit.

6 Fifield, P. (1998) 'Marketing strategy', Butterworth Heinemann in association with CIM, Oxford.

7 Mintzberg, H. (1994) 'The rise and fall of strategic planning', Prentice Hall Europe, Hemel Hempstead.

8 Thurbin, P. (1998) 'The influential strategist', Financial Times Pitman Publishing, London.

9 Buttle, (1996) op. cit.

10 Ibid.

11 Tzokas, N. and Saren, M. (Date unknown) 'Value transformation in CRM', www.crm-forum.com.

12 Grant, A. W. H. and Schlesinger, L. A. (1995) 'Realize your customers' full profit potential', Harvard Business Review, reprint 95503, HBS Publishing, Boston. 
13 Kaplan, R. S. and Norton, D. P. (1996) 'The balanced scorecard', Harvard Business Press, Boston.

14 Christopher, M., Payne, A. and Ballantyne, D. (1991) 'Relationship marketing', Butterworth Heinemann, Oxford.

15 Stone, M. (1998) 'Building customer focused data', Close to the Customer Series, Policy Publications, UK.

16 Buttle (1996) op. cit.

17 Petrissans, A. (1999) 'Customer relationship management: The changing economics of customer relationships', Cap Gemini \& IDC white paper, IDC and Cap Gemini, EMEA.

18 See for example, Stone, M. (1998) 'Targeting high value customers', Close to the Customer Series, Policy Publications, UK.

19 Ibid.

20 Adolf, R., Grant-Thompson, S., Harringtom, W. and Singer, M. (1997) 'What leading banks are learning about big databases and marketing',
McKinsey \& Company, www.crm-forum.com.

21 Several of these are on the web at sites such as www.ibm.com, www.ncr.com and www.crm-forum.com

22 O'Connor, J. and Galvin, E. (1996 and 1997) 'Marketing \& Information Technology', Pitman Publishing, London.

23 Stone, M., Foss, B., Hallick, J., Lowrie, R., Sharman, R. and Simoudis, E. (1997) 'Managing data mining in marketing: Part 1', Journal of Targeting, Measurement and Analysis for Marketing, Vol. 5, No. 2, pp. 125-150, and Part 2, Vol. 5, No. 3. pp. 247-264.

24 Shaw, R. (1998) 'Improving marketing effectiveness', The Economist Books in association with Profile Books, London.

25 Meta Group/Infact Research, 2000.

26 IDL. (2000) '2000 European Business Intelligence Report', IDL on behalf of IBM, Harpenden.

27 McDonald, M. (2000) 'On the right track', Marketing Business, April, p. 29, CIM, Berkshire. 